\title{
NOTES DE LECTURA
}

\section{Ferdinand TönNIES}

\section{Comunitat i associació}

Traducción de J. F. Yvars y M. Ginés. Prólogo de Ll. Flaquer y S. Giner. Edicions 62 / Diputació de Barcelona.

«Clàssics del Pensament Modern», núm. 19, 1984, 285 páginas.

Se ha vertido al catalán la obra cumbre -cuya edición príncipe data de 1887- de Ferdinand Tönnies, clásico de gran influencia en la teoría social, pero sin duda poco conocido en nuestro ámbito,' aungue se observa últimamente una revalorización de sus teotías. Varios son los argumentos originales aportados por Tönnies en Comunidad y Asociación, donde pretende modelar las relaciones interhumanas, reduciéndolas a esquemas clarificadores. El modelo empleado con este fin es básicamente bipolar, como podemos observar a continuación.

Tönnies apunta que la causa generadora de toda conducta humana es la voluntad, entendida ésta en una forma global, como el conjunto de oxientaciones de un individuo hacia el resto de la colectividad. De este modo, las voluntades individuales provocan la acción social. Para T'önnies la voluntad se plantea bajo dos formas diversas: la voluntad esencial o natural mueve a la persona a realizar acciones deseadas por sí mismas, mientras que la voluntad arbitraria ${ }^{2}$ o racional empujaría a la acción que sirve de medio para la consecución de otros fines. Por consiguiente, la voluntad esencial está en relación con el amor, el odio, el miedo... (las que se podrían calificar de conductas y sensaciones «instintivas»), provo-

1. La primera traducción en castellano se editó sólo hace seis años (véase F. Tönnies, Comunidad y asociación, Barcelona, Península, 1979).

2. En la edición en castellano, se había traducido wesenwille por «voluntad natural» y kürwille por «voluntad racional». 
cando en cambio la voluntad arbitraria acciones que obedecen al interés personal, en las que las demás personas entran en el cálculo racional de la acción sólo como medios. En cada individuo se da una combinación de ambas voluntades, que no se presentan en estado puro.

La idea central de Comunidad y Asociación comporta una síntesis de dos doctrinas consideradas hasta la obra de Tönnies itreconciliables: las tesis organicistas habían basado la acción social en lo que Tönnies llamó voluntad esencial, mientras que las contractuales (defendidas por Hobbes, autor muy estudiado por Tönnies) insistían en la importancia de la voluntad arbitraria. Tönnies supera este enfrentamiento con el modelo bipolar comentado, en el que entran en juego las dos voluntades; las acciones sociales oscilan así en un continuo, situándose en un extremo de este continuo las motivadas por la voluntad esencial y en el otro las causadas por la voluntad arbitraria, que permite la consecución de acuerdos o con. tratos entre los individuos. El siguiente avance de la argumentación tönniesiana consiste en pasar de lo individual a lo social. Cuando los individuos se agrupan de acuerdo con sus voluntades esenciales, surgen instituciones ${ }^{3}$ de tipo comunitario, y cuando son impulsados por la voluntad arbitraria, las instituciones son asociativas. Las relaciones de parentesco, vecindad y amistad, entre otras, pertenecerian a la comunidad, en ellas existe una jdentificación total de intereses individuales y colectivos; en cambio, en el comercio, prototipo de institución asociativa, los intereses individuales priman sobre los colectivos. En la asociación sólo se secundan los actos ajenos si éstos sirven a los intereses propios (no existe, pues, la identificación total propia de la comunidad). ${ }^{4}$ Et objetivo de las partes en comunidad es difuso y general, mientras que en asociación es específico. Son éstos los puntos que separan comunidad y asociación, si bien (como señala Parsons) ${ }^{5}$ Tönnies había hecho hincapié en la voluntariedad o involuntariedad de las relaciones y quizás había relegado a un segundo plano otros factores.

Las instituciones de una realidad social determinada suelen presentat*

3. EI término «institución» se usa aquî en la acepción de Gehlen «institución primatia» o, siguiendo la definición de P. Berger y T. Luckmann, «tipificación recíproca de acciones habitualizadas» (La construcción social de la realidad, Buenos Aires, Amorrortu, 1968, p. 76).

4. Existe un fuerte paralelismo entre esta dicotomía y la de solidaridad orgánica / solidaridad mecónica presentada por Dutkheim, o la de solidaridad total / solida. ridad parcial de otros autores.

5. Talcott Parsons (1968:839): Este autor afirma que no todas las formas comu. nitarias nacen involuntariamente. Mientras que de la relación padre-hijo sí nace una comunidad involuntaria, la relación de amistad y el matrimonio son comunidades vo. luntarias. 
se en parte como comunitarias (en tanto tienen como fin las relaciones humanas), en parte como asociativas (en tanto usan como medio estas relaciones). El matrimonio en nuestra sociedad sería un arquetipo de esta mezcla: junto a los aspectos comunitarios de afecto y sexo, encontramos regulaciones jurídico-económicas contractuales que tepresentan la faceta asociativa de esta institución. Sin embargo, la tesis sostenida por Tönnies es que en cada sociedad predominará uno de los dos tipos de instituciones, dándose así organizaciones comunitarias o asociativas (aunque entiéndase que no totalmente comunitarias ni asociativas). El autor afirma que las relaciones de tipo comunitario van perdiendo terreno, pasando a dominar en las organizaciones «modernas» los fenómenos asociativos. Este extremo es puesto en cuestión por L1. Flaquer y S. Giner en su prólogo, donde afirman que la modernidad produce no una progresiva eliminación de las formas comunitarias, sino una privatización de ellas. En cualquier caso, éste sería un tema interesante abierto al debate, en el que se podría introducir la cuestión del nacionalismo (también apuntada en el prólogo) como fenómeno comunitario que no desaparece en las sociedades «modernass.

El análisis tönniesiano de la asociación tiene ciertos puntos en común con el marxista. Se centra principalmente en el desigual intercambio que se realiza en la asociación, según los indivióuos posean o no los medios de producción. Esta desigualdad de partida genera una construcción dividida de la asociación; los individuos que entran en las relaciones de intercambio asociativas pueden pertenecer a la clase capitalista, libre y materialmente capaz de acciones deliberadas, o a la clase obrera, pseudo-libre y sólo formalmente capaz de acciones deliberadas. Asimismo, las reglas institucionales que regulan la asociación vienen matcađas sólo por una de las partes, y no por ambas como sucede en la comunidad. Para controlar las relaciones asociativas, que por su misma esencia precisan un cierto ejercicio de la posición de fuerza que detenta una de las partes, surge el «derecho de contrato», que a su vez actúa de legitimador de la posición de fuerza comentada. Este «derecho de contrato» es opuesto al «derecho familiar», que regula las formas comunitarias y que es una manifestación de lo que Tönnies liama derecho natural. El modelo de ordenación que requiere a largo plazo $\mathrm{l}_{2}$ asociación es el socialismo, que implantará unas normas rígidas que permitirán sustituir los vínculos comunitarios desaparecidos o debilitados.

En toda la obra subyace un juicio moral; Tönnies inclina claramente sus simpatías hacia las relaciones comunitarias, que, con añoranza al verlas decaer, equipara a cierto tipo de moral innata a la persona. La asociación, en cambio, es vista como eliminadora de la moralidad en aras del desarro- 
llo económico. Esta postura se enmarca en la tradición de la "rebedúáa germánica»: como comenta Raymond Aron, ${ }^{6}$ en Alemania se ha tendido a centrar las formas de contestación a la presionante realidad asociativa en ideaies de retorno a la comunidad, a tipos de vida más "naturales». ${ }^{7}$ Este retorno está matizado en Tönnies, que deffende como utopía una agrupación humana basada en el comunismo (que surge de la solidaridad comunitaria) y el socialismo (que es la expresión institucionalizada de las colectividades asociativas modernas). La postura de Tönnies supone un rechazo romántico del capitalismo, observable en diversos autores de su generación en términos parecidos. En su obra «miraba esperanzado al futuro, previendo un orden socialista que tendría los atributos de la Gemeinschaft (comunidad) y que estaría basado en una ética racional y posiblemente en un orden político mundial».

Comunidad y Asociación sólo comenzó a ganar fama después de la Primera Guerra Mundial, cuando en Alemania se acentuó la desilusión por las formas asociativas. Es en este período en el que Spengler publica La decadencia de Occidente. Partiendo del rechazo a la asociación, cuando menos se abrían dos caminos: o afirmar, desde una postura spengleriana, que toda cultura lleva en sí la impronta de la muerte, 0 , como había hecho Tönnies, defender las posibilidades de nuevas formas organizativas que conducirian a la supervivencia de la cultura. El nacionalismo exacerbado alemán de los años treinta y cuarenta fue un intento sui generis de vuelta a algunos aspectos puntuales de la comunidad, pero no del modo que Tönnies había deseado. El mismo resultó víctima de este intento, ya que con el advenimiento del nazismo fue expulsado de la Universidad de Kiel, debido esto a su afiliación al SPD.

JORgE CALERO

\section{REFERENCIAS BIBLIOGRAFICAS}

Raymond Aron. "Comunidad y sociedad», en La sociologia alemana contemporánea, Buenos Aires, Paidós, 1953, 1965, pp. 27-35.

6. Raymond Aron (1965:31).

7. Se podría poner en relación este hecho (motivado por la peculiar evolucion histórica alemana) con la buena acogida que en ese país logtaron en su día los movi. mientos nacionalistas, pero también con el desarrollo que más recientemente han tenido los grupos ecologistas-pacifistas.

8. Rudolf Heberle (1977:386). 
Ronald Fletcher. «Ferdinand Tönnies: From Natural, Living Community to Contrived. Artificial Society", en The Making of Sociology: A Study of Sociological Theory, Londres, Nelson, 1971, vol. 2, pp. $27-83$.

Rudolf Heberle. «Ferdinand Tönnies», en Enciclopedia Internacional de las Ciencias Sociales, Madrid, Aguilar, 1977, vol. 10, pp. 383-387.

Talcott Parsons. «Nota sobre Gemeinschaft y Gesellschaft», en La estructura de la acción social, Madrid, Guadartama, 1968, vol. 2, páginas 836-846.

Bibliografías más extensas se pueden hallar en el artículo "Ferdinand Tönnies», de Rudolf Heberle, así como en la nueva edición en catalán reseñada en el encabezamiento. 